\title{
Sindicatos y política en Chile a mediados del siglo XX. Una relación no exclusiva de socialistas y comunistas. El caso de los obreros de Manufacturas de Cobre, MADECO
}

\author{
Trade unions and politics in Chile in the middle of the 20th century. A non- \\ exclusive relationship of socialists and communists. The case of the workers \\ of Copper Manufactures, MADECO
}

\author{
Sebastián Leiva Flores ${ }^{*}$
}

\begin{abstract}
Resumen: La historiografía marxista ha particularizado en los vínculos de la clase obrera con las corrientes socialistas, minimizando otras influencias. Sin embargo, los trabajadores de mediados del siglo $\mathrm{XX}$, como los primeros obreros de MADECO, estuvieron también identificados o bajo la potencial influencia de otras corrientes sindicales y políticas, relacionándose con ellas en sus fábricas y en las poblaciones que habitaban, matizando y modificando algunos de los rasgos adquiridos en el mundo del trabajo.
\end{abstract}

Palabras clave: Clase obrera, metalúrgicos, partidos políticos, corrientes sindicales, barrio

\begin{abstract}
Marxist historiography has particularized the ties of the working class with socialist currents, minimizing other influences. However, midtwentieth-century workers, like the first MADECO workers, were also identified or under the potential influence of other trade union and political currents, relating to them in their factories and in the populations they inhabited, shading and modifying some of the traits acquired in the world of work.
\end{abstract}

Keywords: Working class, metallurgists, political parties, trade union movements, neighborhood.

Recibido: 16 diciembre 2016

Aceptado: 2 marzo 2017 ${ }^{*}$ Chileno, docente Universidad de Santiago de Chile y estudiante de su programa de Doctorado en Historia,
sebastianleiva72@yahoo.es 
Desde sus comienzos, la CUT fue un organismo absolutamente politizado y con mayoría comunista. Las fuerzas para elegir la mesa directiva en su congreso constituyente, representaban tendencias partidistas claras. Se inscribieron cinco listas. Ganó la presidencia la lista encabezada por Clotario Blest, católico independiente, (que obtuvo trece consejeros) apoyada por comunistas (que ganaron cinco consejeros), socialistas de Chile - allendistas (que lograron tres consejeros), radicales (dos consejeros) y falangistas cristianos (dos consejeros). La segunda lista gobiernista... obtuvo nueve consejeros (cuatro socialistas populares, tres socialistas disidentes y dos ibañistas independientes); los troskistas [sic] encabezados por Ernesto Miranda lograron tres consejeros anarquistas...

Homero Ponce, Historia del Movimiento Asociativo Laboral Chileno ${ }^{1}$

\section{Presentación}

Dejando larga y profunda huella, los historiadores marxistas que desarrollaron sus trabajos entre las décadas del 50 y el golpe de 1973, particularmente Julio César Jobet y Hernán Ramírez Necochea, fueron los primeros que plantearon la relación existente entre el movimiento obrero y el ideario socialista, articulando el desarrollo de la identidad de la clase obrera con los procesos de organización, movilización y politización promovidos fundamentalmente por Luis Emilio Recabarren, las Mancomunales, la Federación Obrera de Chile y el Partido Obrero Socialista. A la par, si bien no ignoraron del todo la influencia que habían alcanzado entre los trabajadores organizaciones o corrientes como el anarquismo, el mutualismo y el Partido Demócrata hasta los primeros años del siglo XX, les supusieron una ascendencia en retirada y/o marginal. $\mathrm{O}$ una influencia negativa, como señaló Ramirez Necochea sobre el anarquismo.

Acotadas entonces aquellas influencias a la prehistoria del movimiento o a gremios específicos, para la historiografía marxista los rasgos identitarios constituidos y solidificados en los años más crudos y agitados de la "cuestión social" - adscripción casi homogénea de la clase a los partidos políticos populares, su opción por un proyecto político de matriz socialista, su disposición conflictiva y beligerante frente al Estado y los sectores dominantes - se hicieron crecientemente hegemónicos, permaneciendo casi intactos tras la incorporación de los trabajadores a las nuevas relaciones y dinámicas que se comenzaron a generar tras la crisis del régimen oligárquico en los años 20.

El norteamericano Peter de Shazo ${ }^{2}$, con nuevas fuentes y enfoques, fue uno de los primeros que problematizó aquellos planteamientos, señalando que, al menos en el caso de Santiago y Valparaíso, en el primer cuarto de siglo predominó el accionar del

\footnotetext{
${ }^{1}$ Homero Ponce, Historia del movimiento asociativo laboral chileno, Santiago, auto edición, 1986, pp. 161 y 162.

${ }^{2}$ Peter de Shazo, Trabajadores urbanos y sindicatos en Chile: 1902 - 1927, Santiago, DIBAM, 2007. 
anarcosindicalismo, sosteniendo a la vez que la presencia e influencia del POS y Recabarren no tenían el alcance nacional que se proyectaba en los textos de los referidos historiadores. Tras él, y cuando traducciones informales y su publicación en español hicieron más conocida su tesis doctoral, otras investigaciones dieron cuenta de la influencia de los libertarios entre los trabajadores, y ello no sólo hasta fines de la década de los 20 como habían sostenido algunos estudios ${ }^{3}$ sino que señalando que ella conservó importante y variada presencia hasta comienzos de los años 40 y en algunos gremios hasta la década siguiente ${ }^{4}$.

Presentes los activistas socialistas y ácratas entre el movimiento obrero en sus años de formación, otro conjunto de estudios, dispersos en sus orientaciones y orígenes, han dado cuenta que en este período otras influencias fueron también impregnando a los trabajadores, proyectándose tras la crisis del régimen oligárquico y el nuevo pacto político social que le siguió, pacto que el grueso de la clase obrera apoyó por convicción, resignación o porque mejoraba en grado diverso sus complejas condiciones de vida y labor. En esa línea, Rafael Sagredo, siguiendo la vida pastoral del padre Fernando Vives, ha dado indicios de la presencia de la actividad de los "católicos sociales" en el movimiento obrero desde comienzos de siglo hasta al menos la década del $30^{5}$, realizando lo mismo Maximiliano Salinas al abordar la vida de Clotario Blest, activista sindical desde los años 20 y dirigente de alcance nacional en los 40, en su momento uno de los participantes de los espacios constituidos por los socialcristianos ${ }^{6}$. Sergio Grez y Jorge Rojas por su parte han dado cuenta de los apoyos e influencias que alcanzaron el Partido Demócrata y el mutualista Congreso Social Obrero, ambos fieles manifestaciones del "liberalismo popular", entre la masa laboral hasta fines de los años 20 y comienzos de los $30^{7}$, mientras que Julio Pinto y Verónica Valdivia, en conjunto y por separado, han revelado el ascendiente que logró sobre ella el oligarca y liberal, de discurso popular, Arturo Alessandri Palma, proyectándose electoralmente él hasta inicios de los años 30 y su impronta hasta avanzado el siglo ${ }^{8}$.

Variadas las orientaciones de las cuales bebió o eventualmente pudo beber la clase obrera en su período de formación y en los primeros años del indistintamente llamado Estado de Compromiso, Benefactor o Asistencial, ellas no desaparecieron con la creación

\footnotetext{
${ }^{3}$ Jaime Sanhueza Tohá, "La Confederación General de Trabajadores y el anarquismo chileno de los años 30”, Revista Historia, vol. 30, Santiago, 1997, pp. 313 a 382.

${ }^{4}$ Víctor Muñoz, Sin dios ni patrones. Historia, diversidad y conflictos del anarquismo en la región chilena (1890 - 1990), Valparaíso, Mar y Tierra Ediciones, 2013.

${ }^{5}$ Rafael Sagredo, Escritos del Padre Fernando Vives Solar, Santiago, DIBAM, 1993.

${ }^{6}$ Maximiliano Salinas, Clotario Blest, profeta de dios contra el capitalismo, Santiago, ediciones REHUE, 1987.

${ }^{7}$ Sergio Grez, El Partido Democrático de Chile. Auge y caída de una organización político popular (1887 1927), Santiago, LOM Ediciones, 2016; Jorge Rojas, La dictadura de Ibáñez y los sindicatos (1927 - 1931), Santiago, DIBAM, 1993.

${ }^{8}$ Julio Pinto y Verónica Valdivia, ¿Revolución proletaria o querida chusma? Socialismo y Alessandrismo en la pugna por la politización pampina (1911 - 1932), Santiago, LOM Ediciones, 2001; Julio Pinto, Trabajos y rebeldías en la pampa salitrera, Santiago, Editorial Universidad de Santiago, 1998; Verónica Valdivia, "Yo, el León de Tarapacá. Arturo Alessandri Palma, 1915 - 1932”, Revista Historia, vol. 32, Santiago, 1999, pp. 485 a 551.
} 
de la unitaria Confederación de Trabajadores de Chile (CTCH) en 1936 ni con su división y consiguiente debilitamiento del movimiento sindical exactamente una década después. Así, llegado el medio siglo y en pleno proceso de industrialización, entre la clase obrera fabril se manifestaron un abanico de influencias, ampliándose estas en las comunas donde estaban asentadas sus industrias y las poblaciones que habitaba, encontrándose en ellas con fuerzas políticas que tenían escasa presencia en el mundo del trabajo, diversificándose el campo en torno al cual pudieron echar mano a la hora de buscar mejorar sus condiciones de vida y labor e intervenir en la actividad colectiva. Los obreros de una importante industria metalúrgica creada en aquellos años, Manufacturas de Cobre S.A, MADECO, fundada en 1944 en la comuna de San Miguel, fueron expresión de todo ello, encontrándose en su sindicato, gremio y Central con socialistas, comunistas, anarcosindicalistas y católicos, mientras que en sus barrios establecieron relaciones con militantes del antiguo y "meritocrático" Partido Radical y el vetusto pero no desaparecido Partido Democrático.

Las páginas que siguen, correspondientes a un avance de mi tesis doctoral ${ }^{9}$, se refieren a ese conjunto diverso de influencias y herencias, pretendiendo en ellas proponer un enfoque, sugerir una hipótesis y plantear una inquietud: respecto a lo primero, sin cuestionar la importancia vital del trabajo, lo cierto es que hacia mediados de siglo ya se había instituido un conjunto de normas, hábitos y políticas que permitían disponer de no pocas horas para el esparcimiento con los compañeros de labor, la vida familiar y la actividad barrial, siendo por lo tanto importante considerar las relaciones e identificaciones que se generaron en esas dinámicas y espacios.

Relacionado con ello, y a propósito de la hipótesis, podemos suponer que hacia mediados de siglo el mundo de los trabajadores era un mundo en varios sentidos diverso, expresándose un abanico de organizaciones políticas tanto en sus ámbitos de labor como en los barrios donde vivía, manifestándose múltiples formas y dinámicas de acción, y sustentándose heterogéneos discursos y preocupaciones. Aquella diversidad presente en el mundo de los trabajadores no fue una situación puramente episódica o particular, correspondiendo más bien a un rasgo de alcance estructural, influyendo en grado diverso en la configuración identitaria de la clase obrera nacional e incidiendo en la forma en que esta se fue posicionando respecto al Estado y los sectores dirigentes.

Por último, al menos a quien escribe estas líneas no le termina de impresionar, en comparación a lo que era su propio "sentido común historiográfico" sobre el período y el actor - pensando en Richard Hoggart, construido en tiempos de dictadura, en una familia de origen obrero e identificada con la izquierda -, la manifiesta diversidad que expresaba el movimiento popular a mediados del siglo XX, surgiendo la pregunta sobre los límites presentes en la construcción del relato historiográfico y su impacto sobre quienes piensan, planifican y vivencian la política entre o para los trabajadores.

\footnotetext{
${ }^{9}$ El proyecto de tesis se titula Vida y Trabajo de la clase obrera chilena. Los trabajadores textiles y metalúrgicos entre las décadas de 1930 y 1960, abarcando un período del movimiento obrero conocido más bien en sus líneas gruesas, del cual se ha priorizado en la investigación de los trabajadores del carbón y el cobre y en dinámicas y espacios como las huelgas y las centrales sindicales.
} 


\section{Panorámica del período. Las décadas del 40 y 50}

Desde fines de la década del 30 el Estado chileno comenzó a sistematizar una política de desarrollo industrial que, hasta la creación de la CORFO en 1939, había carecido de orientaciones y metas de largo aliento. Aquella política, que buscaba disminuir la dependencia de las importaciones a la vez que procurar el desarrollo de los factores productivos nacionales, se materializó a través de la implementación de un conjunto de medidas (no del todo orgánicas y/o suficientes) que redundaron en una importante expansión del sector y en el aumento de su participación en la economía nacional, creciendo en un $7.5 \%$ anual entre 1940 y 1953, mientras que sus índices en el PGB del mismo período se elevaban del $16.7 \%$ al $23.7 \%$.

Del sector, destacó el crecimiento de los rubros metalúrgico, textil y de alimentos, fiel reflejo de lo que eran las posibilidades de la industria nacional, las necesidades del mercado interno y las prioridades fijadas por el Estado, convirtiéndose algunos de sus establecimientos en íconos de aquellas políticas. La industria MADECO se corresponde con ello, iniciando su funcionamiento el año 1944 a partir de la inversión público - privada (CORFO / hermanos Simonetti), aprovechando beneficios como la exención de algunos impuestos y la sobretasa aduanera a la producción extranjera.

Diversos factores incidieron sin embargo en el freno de aquel crecimiento ya hacia comienzos de los 50. La limitada dimensión del mercado interno, las dificultades para competir en los mercados foráneos, algunas trabas puntuales derivadas de situaciones externas (la Guerra de Corea), entre otros, deprimieron la actividad industrial, impactando ello directamente en la estabilidad y calidad del trabajo de los obreros metalúrgicos, advirtiendo estos de la huelga o haciendo uso de la misma, a la par que articulaban espacios y actividades para defender sus trabajos.

Pero en los últimos años de los 40 y primeros de los 50 los operarios metalúrgicos debieron enfrentar otros problemas no directamente vinculados con sus espacios específicos de labor o con aquellas que debía tratar el sindicato, conectándose a partir de ello con trabajadores de otros rubros y con los habitantes de las comunas donde estaban sus fábricas (y sus propios hogares). Uno de esos problemas fue la precarización general del trabajo, eliminándose o disminuyéndose beneficios, congelándose salarios y despidiéndose operarios, aumentando con ello la explotación laboral, la cesantía y el conflicto sectorial. Un segundo problema se relacionó con la legislación que restringió las libertades públicas, pensada inicialmente para frenar la actividad del Partido Comunista pero usada indistintamente contra los sindicalistas cuando el gobierno lo procuraba. Por último, un problema que afectó al conjunto de los sectores populares, la "carestía de la vida", ello producto de una inflación que, mientras entre 1946 y 1950 alcanzaba el 20\% anual, en 1953 llegaba al 40\%, configurándose un escenario de persistente devaluación de los ingresos, ahorros y fondos de las familias obreras por el encarecimiento de la vida, en el preciso momento en que el trabajo escaseaba o se precarizaba.

En este poco promisorio contexto y enfrentando estas heterogéneas problemáticas los obreros de MADECO iniciaron su participación, en las medianías del siglo, en diversos espacios e instancias comunales y gremiales, volcando buena parte de su actividad y de su 
demanda más allá de su propia labor, de los lindes de la fábrica y de la sede sindical, incorporando a su ser y hacer valoraciones, prácticas y orientaciones de aquellos con quien se fueron relacionando.

\section{Los trabajadores de MADECO tras los muros de la fábrica}

Iniciada la actividad de MADECO en 1944, un año después los poco más de 200 obreros con que partió la industria fundaron su sindicato, y lejos de preocuparse exclusivamente de su situación, se las arreglaron no sólo para mejorar sus condiciones de trabajo y satisfacer algunas necesidades de la vida cotidiana, sino además para pronunciarse y movilizarse por la compleja situación económica y política de mediados de siglo, vinculándose en ese esfuerzo con la comunidad laboral y territorial con la cual compartían problemáticas y expectativas.

A pesar de formarse el sindicato de MADECO recién el año 45, ya en abril de 1946 uno de sus trabajadores - Juan Givovich, como Secretario de Finanzas - integraba la directiva de la CTCH comunal de San Miguel, compartiendo funciones con obreros del sector de materiales para la construcción y de alimentos y bebidas. El vínculo no se quedó ahí, participando dos obreros de MADECO como delegados en el congreso que la central realizó en diciembre de ese mismo año ${ }^{10}$, Rufino Herrera y Armando Rozas. Las propuestas presentadas en ese evento fueron reafirmadas en la conmemoración del $1^{\circ}$ de Mayo del año 47, entregándole la $\mathrm{CTCH}$ al presidente Gabriel González Videla un documento con sus demandas más sentidas, señalándose varias que superaban el ámbito estricto del trabajo y que ya estaban (o estarían) entre los temas que preocupaban a los trabajadores de MADECO: el freno a las alzas, la reorganización del Comisariato de Subsistencias, la construcción de viviendas y la "defensa de la democracia", esto último a propósito de su rechazo a las leyes que comenzaban a limitar el accionar de algunos militantes de izquierda y sindicalistas ${ }^{11}$.

A fines de ese año 47 la misma fracción de la CTCH (la influida por el PC) realizó un nuevo encuentro, participando en él la Federación Industrial de Obreros Metalúrgicos, federación que fue cobrando creciente importancia en la medida que la central se debilitaba por sus divisiones internas y la represión estatal, asumiendo expreso protagonismo en ella los obreros de MADECO desde 1951.

Nacida en 1932, la Federación Metalúrgica se encontraba dividida a mediados de la década siguiente, existiendo la Unión Provincial Metalúrgica, de orientación socialista, y la Federación de Obreros Metalúrgicos, con influencia comunista, incorporando ambas entre sus preocupaciones, además de las cuestiones propiamente gremiales, la situación económica y política del país. Ya en un evento de agosto de 1945 la Unión Provincial manifestó inquietud por la inestabilidad económica y sus efectos sobre el diario vivir de los trabajadores, llamando a apoyar a quienes estaban siendo expulsados de los lugares donde vivían por no pagar sus arriendos, a luchar contra la especulación y a exigir el

\footnotetext{
${ }^{10}$ El Siglo, abril y diciembre de 1946.

${ }^{11}$ Ver El Siglo, "Sindicato MADECO luchará contra las alzas de tarifas", 19 de abril de 1947, p. 7.
} 
abaratamiento de las subsistencias. Dos años después, en agosto del 47, un ampliado de la Federación Metalúrgica decidió sumarse al Comando Nacional Contra las Alzas ${ }^{12}$.

En octubre de 1950, y cuando los efectos de la división en el mundo sindical se hacían patente en la dificultad para defender las condiciones de vida y trabajo de la masa laboral, la Federación emprendió la realización del V Congreso Metalúrgico, reflejando sus temas y resoluciones la mutua influencia que se fue manifestando entre la Federación y el sindicato de MADECO. Los tópicos centrales fueron "condiciones de vida y trabajo", "carestía de la vida y legislación social", "defensa de las libertades y derechos sindicales" y "lucha por la industria nacional, por la paz y contra la guerra", destacando de las resoluciones algunas que ya estaban impulsando los trabajadores de MADECO. Entre otras, la asignación del "salario familiar" y la entrega de una subvención a aquellos obreros que debían realizar el servicio militar (obtenidas en MADECO en 1944 y 1945, respectivamente), el freno a los proyectos "anti-inflacionistas" y el fin del intervencionismo norteamericano" 13 .

Aquella coincidencia en las preocupaciones, facilitada por la presencia de sindicalistas del PC a la cabeza de la Federación Metalúrgica y el sindicato de MADECO, llevaron a la creciente participación de este último en el gremio, haciéndose parte de la convocatoria a una conferencia provincial en agosto del 51 donde se reafirmaron las cuestiones principales tratadas en el V Congreso, entre ellas el fin a la carestía de la vida y la derogación de las leyes represivas, el apoyo a las luchas por la paz y la promoción de la industria nacional ${ }^{14}$. Al finalizar el evento y realizarse la elección de la nueva directiva, la preocupación de los obreros de MADECO por participar en ella quedó graficada al incorporar a un importante dirigente de los suyos, Benigno López, presidente de su sindicato entre 1946 y 1948, a la directiva entrante como Secretario de Conflictos.

La creciente incorporación a la Federación Metalúrgica no fue sólo una cuestión de dirigentes, mostrándose particularmente activos los trabajadores de MADECO en los primeros años de los 50, sumándose a diversas iniciativas impulsadas por la federación y por otras organizaciones, promoviendo a su vez otras acciones a nivel de trabajadores y comuna. Así, además de ser uno de los promotores de la formación de un "Comité de Unidad Sindical" en San Miguel en marzo de 1950, participaban a través de la Federación Metalúrgica en el Movimiento Unitario Nacional de Trabajadores, una de las instancias que procuraba llenar el vacío que había dejado la división de la $\mathrm{CTCH}^{15}$.

En octubre de 1952, y tras haber contado con el fuerte respaldo de la Federación en sus iniciativas, los obreros de MADECO dieron cuenta de la importancia que le asignaban en su quehacer, participando activamente en el VI Congreso Nacional Metalúrgico, asumiendo como Secretario General del evento uno de sus compañeros, José González, e

\footnotetext{
${ }^{12}$ El Siglo, agosto de 1945 y agosto de 1947. Sobre esta última, ver "Nuestra patria como protección piden para Celestino Uriarte, metalúrgicos”, 29 de agosto de 1947, p. 5.

${ }^{13}$ La Opinión, "Quinto Congreso Nacional prepara la Federación de Obreros Metalúrgicos", 14 de julio de 1950, p. 4. También, el periódico Democracia del mes de octubre.

${ }^{14}$ Democracia, "Defensa de la industria nacional plantea convocatoria de conferencia metalúrgica", 27 de junio de 1951, p. 2, y Democracia, "Escala móvil de salario", 12 de agosto de 1951, p. 1.

15 Democracia, marzo de 1950; La Opinión, "La asamblea de los obreros de MADECO ratificó apoyo de solidaridad gremial", 14 de julio de 1950, p. 2.
} 
integrándose a la nueva directiva un segundo madequino, Armando Rozas, como Secretario de Finanzas ${ }^{16}$.

La notoria actividad de los obreros de MADECO a partir de 1950 no se acotó exclusivamente a su gremio, materializándose relaciones con trabajadores con los cuales no compartían oficio sino territorio. La comuna de San Miguel.

Con un movimiento obrero fragmentado, con leyes que dificultaban la actividad sindical y con patrones que aprovechaban la situación para quitar o negar beneficios, las coordinaciones fueron ganando espacio, participando protagónicamente en una de ellas - el "Comité de Unidad Sindical" - los trabajadores de MADECO. En su sede sindical precisamente se realizó la convocatoria para su creación, haciéndose parte de la idea delegados y dirigentes de diversos rubros, proponiéndose sencilla y centralmente la colaboración para enfrentar las problemáticas que los aquejaban ${ }^{17}$.

El Comité de Unidad Sindical desplegó, hasta el momento en que la formación de la CUT nacional y comunal lo hizo innecesario, una actividad amplia y diversa, combinando la vertiente gremial que le dio origen con la politización de sus demandas, cuestionando crecientemente aquello que atentaba contra los trabajadores - el encarecimiento de la vida por ejemplo -, permitiendo en poco tiempo la convergencia de reclamos y sujetos. Los beneficiarios directos y primeros de su accionar fueron trabajadores municipales, textiles y del metal (MADECO entre ellos), organizando concentraciones para difundir sus conflictos a la vez que prestarles apoyo moral y económico. En este mismo ámbito de la difusión y apoyo de los conflictos, el Comité organizó la conmemoración del $1^{\circ}$ de Mayo en 1952, integrando la comisión respectiva el presidente del sindicato de MADECO en $1951^{18}$.

Aquel apoyo entre trabajadores para defender su fuente laboral pronto trascendió hacia otros sujetos de la comuna y hacia otros problemas de quienes la habitaban, extendiendo en ese proceso los obreros de MADECO sus relaciones hacia actores y organizaciones que si bien no le eran del todo ajenas, sí le eran relativamente lejanas (la Junta de Vecinos de la población MADECO se formó en 1952), ampliando y diversificando, social y políticamente, su red de identificación e influencia.

El encarecimiento de las subsistencias fue el segundo eje articulador de la actividad del Comité, convocando a un mitin en mayo del 51 para discutir el tema, invitando a parlamentarios, autoridades de la comuna y dirigentes de instituciones obreras y de pobladores. Dos meses más tarde, en julio, se reunieron el Comité de Unidad y el Frente Comunal de la Vivienda de San Miguel para preparar su participación en el mitin contra las alzas del 29 de ese mes, creándose en esos mismos días en la comuna un "Comando contra las Alzas", participando de la instancia el Comité de Unidad Sindical y el Frente Comunal de la Vivienda, sumándose la "Alianza Femenina" 19. En 1953 se retomó la idea, formándose en el transcurso del segundo semestre, por iniciativa del Comité de Unidad Sindical, un "Comité contra las alzas", participando en él hacia fines de año el Sindicato de Ferias Libres, la Agrupación Comunal de Pobladores (con influencia socialista) y diversos

\footnotetext{
${ }^{16}$ Democracia, "Congreso metalúrgico acordó apoyar creación central única”, 24 de octubre de 1952, p. 4.

${ }^{17}$ Democracia, "Comité relacionador de la comuna de San Miguel", 13 de marzo de 1950, p. 8.

${ }^{18}$ Ver en Democracia, marzo de 1952; El Siglo, marzo de 1953; Democracia, abril de 1952.

${ }^{19}$ Democracia, mayo, julio y agosto de 1951 .
} 
sindicatos y poblaciones de San Miguel. Y como había ocurrido con la CTCH comunal y la Federación Metalúrgica, los obreros de MADECO asumieron responsabilidades en la instancia coordinadora, incorporando a su directiva a uno de sus compañeros ${ }^{20}$.

La preocupación de los obreros de MADECO por situaciones que estaban más allá de los muros de la fábrica y de las tareas centrales del sindicato se relacionó, además de las condiciones políticas y económicas de estos años, con sus propios vínculos con las organizaciones que participaban de la dirección del Estado. Sin ir más lejos, en las elecciones presidenciales de 1946 la directiva del sindicato apoyó, "por unanimidad", la candidatura del radical Gabriel González Videla ${ }^{21}$, saludando luego su elección con una inserción en el periódico El Siglo, del PC, uno de los integrantes del nuevo gobierno.

Así como había trabajadores comunistas, también los había socialistas. En febrero del 48 la seccional de San Miguel de ese partido llamó a sus brigadas a participar de un acto de la CTCH, identificando entre ellas a la que existía en MADECO, mientras que el año 50 convocó a sus "brigadas metalúrgicas" a una actividad interna, citando entre ellas nuevamente a los obreros de MADECO ${ }^{22}$.

Para las elecciones presidenciales de 1952 las adscripciones políticas se hicieron más variadas. Tempranamente, el 19 de octubre de 1951, se presentó en la fábrica (y en su población) el candidato de la derecha, el liberal Arturo Matte Larraín, siendo acompañado por los industriales y representantes de los trabajadores. En 1952 el turno fue de Carlos Ibáñez, invitado por el comando ibañista existente en la industria, generándose una discusión entre los miembros de la directiva del sindicato por haber quedado la idea, según el Comité Industrial Allendista, que era la instancia sindical quien había organizado la actividad. Esa tercera candidatura, la del socialista Salvador Allende, fue fuertemente apoyada por el sindicato de MADECO, integrando el Comando Comunal del Frente del Pueblo, participando en su proclamación en la comuna en enero del 52 y creando su propio comité electoral en la fábrica ${ }^{23}$.

Fuera de la coyuntura electoral, hacia 1953 maduró la relación de los trabajadores de MADECO con la Asociación Sindical Chilena (ASICH), organización de matriz católica que tenía fluidas relaciones con la Falange Nacional, participando el presidente del sindicato de MADECO en la formación, en el local de la ASICH, del "Comando unificado de lucha por las reivindicaciones obreras", compartiendo funciones con obreros textiles y de la carne ${ }^{24}$.

De las fuerzas políticas o sindicales referidas, todas ellas (a excepción de los liberales) tuvieron representación en la directiva del sindicato, mostrando Joel Stillerman cómo se distribuyeron en los años 40 y 50. Como veíamos, un obrero vinculado a la ASICH presidió el sindicato durante 1953, compartiendo la directiva con un trabajador comunista y dos ibañistas, siendo estos últimos quienes conducían el sindicato en 1952,

${ }^{20}$ El Siglo, "Contra las alzas: ampliado a las 19 horas hoy, en San Miguel", 15 de diciembre de 1953, p. 2. y "Preparan congreso local de la CUTCH de San Miguel", 17 de diciembre de 1953, p. 5.

${ }^{21}$ El Siglo, "Combativos comités se unen a los miles ya existentes", 26 de mayo de 1946, p. 2.

${ }^{22}$ La Opinión, febrero de 1948 y agosto de 1950.

${ }^{23}$ La Opinión, octubre de 1951; Democracia, agosto de 1952; Democracia, enero y abril de 1952.

${ }^{24}$ Tribuna Sindical, "Se formó el Comando Unificado de Lucha por las Reivindicaciones Obreras", año IV, febrero de $1953, \mathrm{~N}^{\circ} 40$, p. 6. 
acompañándolos sólo un activista del PC. Hasta esos años sin embargo la hegemonía había sido de la izquierda, predominando desde 1945 hasta 1948 los activistas socialistas, perdiendo fuerza por las divisiones de su partido y la incorporación de obreros comunistas a la empresa, logrando mayoría los sindicalistas del PC en las directivas de los años 49, 50 y $51^{25}$.

Por último, se puede señalar que los trabajadores de MADECO estuvieron en contacto y/o se identificaron en sus espacios gremiales principalmente - no "únicamente" con organizaciones de izquierda, acercándose en su relación con los trabajadores y vecinos de la comuna a fuerzas que, mientras en el ámbito sindical tenían escasa presencia directiva, en las organizaciones comunales mantenían gran ascendencia y representación, encontrándose en ellas los obreros de MADECO con antiguos, activos y legitimados militantes radicales, demócratas e ibañistas.

\section{Los obreros en sus comunidades. La población MADECO y sus barrios circundantes}

Hasta mediados del siglo XX, la construcción de poblaciones obreras por parte de los empresarios fabriles fue más bien una cuestión excepcional, no existiendo en las urbes las condicionantes geográficas o de acceso a la fuerza de trabajo que había obligado a los empresarios mineros a construirlas. Casos como los de las textiles Bellavista Oveja Tomé y Fábrica de Paños Bellavista Tomé, de la localidad homónima, que construyeron sus primeras poblaciones obreras en la década del 30 , fueron más bien aislados ${ }^{26}$, comenzando a hacerse más común aquella iniciativa desde la creación de la Caja de Habitación Popular en 1943. Bajo dependencia del Ministerio del Trabajo, la Caja de Habitación Popular estaba orientada a la construcción y fomento de la edificación de viviendas "baratas y salubres", huertos obreros y familiares, estableciendo que el 5\% de las utilidades de las empresas debía destinarse a la construcción de viviendas para sus trabajadores, surgiendo a partir de ese momento poblaciones obreras de diversas empresas, entre ellas MADECO.

La población MADECO fue construida en las cercanías de la fábrica, constituyendo un gran barrio al albergar una plaza y los estadios MADECO y MADEMSA, iniciándose la instalación de sus primeras familias, como informó La Comuna ${ }^{27}$, en el transcurso de 1947, cuando su edificación aún continuaba. En 1951, al núcleo original de 120 viviendas se le estaban sumando otras 50 que estaban en construcción, concibiéndose en el diseño original, según Democracia, llegar a las 500 casas $^{28}$.

\footnotetext{
${ }^{25}$ Joel Stillerman, From solidarity to survival. Transformations in the Culture and Styles of Movilization of Chilean Metalworkers under Democratic and Authoritarian Regimes, 1945 - 1995, Nueva York, New School for Social Research, 1998, p. 136.

${ }^{26}$ Sobre ellas, se pueden consultar los trabajos de Diego Morales, El Paternalismo Industrial en la fábrica de Paños Bella-vista Tomé, 1910 - 1935 (2013) y el de Patricio Quinteros, Antecedentes para una historia de la industria textil de Tomé durante la primera mitad del siglo XX (2001).

27 La Comuna, "Visita del Presidente de la República a la fábrica MADECO", año VI, N 212,22 de noviembre de 1947.

${ }^{28}$ Democracia, "'MADECO tiene capacidad inmediata para elaborar 80.000 toneladas de cobre", 12 de julio de 1951 , p. 1. Según la nota, el plano de la población, además de proyectarse hasta las 500 casas, tenía
} 
Sin ser particularmente visible la actividad de la población MADECO en sus primeros años ${ }^{29}$, probablemente porque los esfuerzos de sus habitantes se concentraron en avituallar sus propias viviendas y su entorno, estos tuvieron la oportunidad de incorporarse a las actividades promovidas por otros referentes y espacios que se encontraban cercanos a la población, alimentando e influenciando esta circunstancia, en grado diverso, la experiencia de los obreros de MADECO y sus familias.

Circunscrita a unas seis o siete cuadras de oriente a poniente y tres o cuatro de norte a sur las instalaciones de la fábrica, la sede del sindicato, las casas de la población y su estadio, el barrio MADECO estaba rodeado por una serie de poblaciones y sectores muy activos y organizados, entre ellos las poblaciones Julio Dávila - Esteban Vega, Germania, Mussa y Recreo, las dos primeras ubicadas hacia el norte y las dos últimas en dirección sur.

La población Julio Dávila - Esteban Vega surgió de la compra de un terreno por la cooperativa homónima en 1948, cooperativa formada fundamentalmente por vecinos de La Legua y encabezada por dos artesanos del mimbre que legaron su nombre al nuevo asentamiento. Como muchas de las poblaciones que nacían de la compra de sitios, su dueño original no cumplió las obras de urbanización comprometidas, denunciando sus vecinos, en diversos años, la falta de pavimentación, alumbrado público y agua potable, solicitando a su vez la instalación de una feria libre en el sector y la extensión de la locomoción colectiva hacia la zona. En 1953, otro motivo convocó sus esfuerzos: la "conferencia por la paz" de la dirigente comunista Julieta Campusano organizada por el Comité de Partidarios por la Paz de la población en el mes de abril ${ }^{30}$. En la población Germania por su parte, una Comunidad de Aguas y Adelanto Local se reunió a fines de noviembre de 1947 para discutir el tema de la seguridad del barrio, a la par que los vecinos llamaron a una concentración para discutir el tema de la vivienda, invitando a delegados de La Legua y de sectores colindantes - Varas Mena y Aurora Mira -, además de representantes del congreso, de la municipalidad y de la Caja de Habitación Popular ${ }^{31}$.

La población Mussa, colindante a la población MADECO, participaba del Frente Nacional de la Vivienda, organizando su Consejo Local una concentración por el tema del agua potable en febrero de 1951, invitando a ella al consejero de la Caja de la Habitación Popular, regidores, parlamentarios y otras autoridades ${ }^{32}$. A su vez, en la población Recreo su Sociedad Femenina de Cooperación Social se mostró particularmente preocupada por las problemáticas políticas y sociales, organizando en marzo de 1950 una velada artística para ir en ayuda de los afectados por la ley maldita, y en enero de 1951 realizó un festival en beneficio del policlínico de la población. Sólo meses después, en mayo, llevó a cabo una colecta para ir en ayuda de unas operarias textiles en huelga, y en octubre del mismo año la

pensado un policlínico, un hospital, un mercado modelo, un salón teatro, un campo de deportes y plazas. Según Joel Stillerman, 300 fueron finalmente las viviendas construidas en la población MADECO. Op. cit.

${ }^{29}$ En la prensa, además de encontrarse la referencia a la creación de la Junta de Vecinos, se conoció de la presentación que hizo en la Plaza MADECO, a principios de 1953, la Orquesta Sinfónica de Chile, ello bajo la organización del Instituto de Extensión Musical de la Universidad de Chile.

${ }^{30}$ Municipalidad de San Joaquín, "Población Julio Dávila - Esteban Vega Ltda", Aquí hacemos historia: crónicas y relatos de San Joaquín, Santiago, 1995, pp. 67 a 80.

${ }^{31}$ La Comuna, noviembre 1947; El Siglo, noviembre de 1947.

${ }^{32}$ La Opinión, 18 de febrero de 1951. 
población fue sede de un acto preparatorio del Congreso por la Paz de San Miguel que se concretaría en la segunda quincena del mes. No dejando dudas sobre las orientaciones políticas de quienes impulsaban los esfuerzos, el Frente de Juventudes Populares de la población proclamó en ella a los candidatos del Frente del Pueblo para las elecciones de regidores de marzo de $1953^{33}$.

Importante y sistemático aquel accionar que se observaba en las poblaciones vecinas a MADECO, la unión vecinal que las agrupaba, la Unidad Vecinal San Miguel Oriente, supo y pudo impulsar varias de esas demandas, vinculando a los obreros que vivían en ellas con corrientes y discursos que en el mundo del trabajo tenían escasa tribuna.

Si bien esta gran unidad vecinal existía desde mediados de la década de los 40, observándose en ese momento un gran predominio de los radicales ${ }^{34}$, su protagonismo más visible se alcanzó desde comienzos de los 50. En el primer semestre de 1952 la directiva de la Unión Vecinal invitó a los dirigentes del área a discutir sobre la situación de abandono de sus barrios y entornos, fijando dos objetivos, la constitución de un "Consejo Consultivo" y la definición de un programa de acción, el cual se vinculaba con las principales demandas del sector - ensanche de avenidas, mejoramiento de la locomoción ${ }^{35}$. A la convocatoria le siguió, en el mes de julio, una reunión de los dirigentes de la Unión Vecinal y las directivas de las poblaciones del sector con las autoridades relacionadas con algunas de sus demandas, participando el Ministro de Salubridad, el Intendente de Santiago y el Director General de Transporte y Tránsito Público.

Durante 1953 la actividad de la Unión Vecinal se asentó y extendió, realizando reuniones y gestiones que la llevaron a ampliar sus interlocutores y visibilizar sus demandas, y si bien a muy pocas de ellas se les dio respuesta positiva, fue sistematizando su funcionamiento y diversificando sus relaciones. En el mes de abril se organizó una conferencia donde si bien se repitieron las quejas que se venían planteando, se hizo frente a potenciales aliados o quienes debían atender al problema, participando en ella el alcalde de la comuna (radical), regidores (radicales y socialistas), parlamentarios (el diputado socialista del distrito) y dirigentes de muchos asentamientos ${ }^{36}$.

La Unión Vecinal, si bien tendió a concentrarse en el tema sectorial y local, de todas formas estableció vínculos o identificaciones políticas, expresando a fines de 1952 sus antiguas relaciones con el radicalismo al definir su formal apoyo a algunos de sus candidatos en las elecciones de regidores de marzo del 53, Carlos Valdovinos y Severino Pazos entre ellos, adoptando esa opción bajo la divisa "Por la Unión y el Progreso de los barrios de San Miguel”. Y en términos de organizaciones de pobladores, en junio de ese

\footnotetext{
${ }^{33}$ Ver en Democracia o El Siglo de marzo de 1950, enero de 1951, mayo de 1951, octubre de 1951 y marzo de 1953 .

${ }^{34}$ La directiva electa en 1947 era encabezada por el radical Carlos Valdovinos.

${ }^{35}$ Democracia, "Importante ampliado de vecinos del sector oriente de comuna de San Miguel", 11 de abril de 1952, p. 4. La convocatoria aludía directamente a los vecinos de las poblaciones La Legua, Mussa, Madeco, Malaquías Concha y Colón América, mencionando una nota de febrero de 1953 a otras poblaciones que la integraban, entre ellas Germania, Variante San Diego, Santa Rosa de Macul, Marta Inés, Recreo, Carmen Mena, Navarrete, RCA Víctor, El Carmen y Chile.

${ }^{36}$ El Siglo, "Abovedamiento del canal Santa Rosa piden los pobladores de San Miguel”, 7 de abril de 1953, p. 8.
} 
año 53 participó en el Segundo Congreso Provincial de los Pobladores de Santiago, un referente asociado con los socialistas, incorporándose uno de sus delegados a la directiva del evento, compartiendo responsabilidades, entre otros, con un poblador de Nueva La Legua y uno de Agregados de La Legua ${ }^{37}$.

\section{La comuna y el municipio}

En tanto comuna en crecimiento ${ }^{38}$, no fueron pocos los problemas que debió enfrentar el municipio. A la vez, no fueron pocas las razones que tuvieron los vecinos para crear organizaciones y tender puentes o presionar al cuerpo edilicio para darles solución, siendo relativamente común el diálogo, la articulación y la cooperación, sin descontar el conflicto, entre las autoridades de la municipalidad y los habitantes de San Miguel, ambos activamente preocupados por el "progreso comunal".

El municipio, donde el protagonismo recayó en fuerzas políticas distintas a aquellas que orientaban a las macro organizaciones de obreros y pobladores, hizo no pocos esfuerzos por el progreso comunal, promoviendo iniciativas en diversas direcciones. En lo prioritario, y concordante con la demanda vecinal, emprendió obras que estaban a su alcance - construcción de plazas y policlínicos, eliminación de basurales, apertura de calles -, demandando a su vez aquello que le correspondía al Estado, como la infraestructura sanitaria y vial mayor.

El accionar de la municipalidad al parecer no pasó desapercibido. Así, el radical Carlos Valdovinos, dirigente vecinal, regidor y alcalde en diversos años de las décadas del 40 y 50, recibió sucesivos homenajes durante 1953, agradeciéndole en específico los vecinos de la población Miguel Dávila sus gestiones para acceder a diversos servicios, como vigilancia policial, educación, alumbrado público y locomoción ${ }^{39}$. A su vez, comités vecinales y clubes deportivos de la época tomaron el nombre de sus ediles - Club Ciclista Juan Aravena (demócrata), Comité de Vivienda Luis Reinoso (agrario laborista) y Mercedes Miranda (comunista) -, mientras que algunas juntas de vecinos los nombraron en sus "directorios honoríficos", como la Unión Vecinal San Miguel Oriente a Carlos Valdovinos.

Los nombrados - Aravena, Reinoso, Miranda y Valdovinos, alcaldes o regidores entre 1944 y 1953 - dan cuenta de la heterogénea representación política que se hizo presente en el municipio, manifestándose sin embargo un claro predominio de dos organizaciones que desde fines del siglo XIX habían tejido relaciones con una diversísima clase media y algunos segmentos de trabajadores, como los artesanos y los obreros calificados: el Partido Radical y el Partido Democrático. Los partidos clásicos de la

\footnotetext{
${ }^{37}$ El Diario Ilustrado, noviembre de 1952; El Siglo, “Ayer se inauguró Congreso Provincial de Pobladores", 20 de junio de 1953, p. 8.

${ }^{38}$ En 1920 la población de la comuna ascendía a 13.234 personas, subiendo a 35.913 en 1930 . Una década después, en 1940, esa cantidad alcanzó los 65.463 vecinos, elevándose a 81.804 en 1948. Poco después, el censo de 1952 arrojó la cifra de 145.541 vecinos.

${ }^{39}$ El Imparcial, "Vecinos de la pobl. Miguel Dávila rendirán homenaje al ex alcalde", 23 de junio de 1953, p. 4.
} 
izquierda chilena, el comunista y socialista, tenían una representación más bien débil en la dirección de la comuna, superando por poco a organizaciones partidarias del "orden" y la "tradición", como los ibañistas y conservadores.

En 1947 fue electo alcalde el demócrata René Aravena, siendo acompañado en la dirección de la comuna por un segundo demócrata, un radical, un conservador y una militante comunista. A su vez, en 1950 alcanzó la dirección comunal el radical Carlos Valdovinos, conformando el cuerpo de ediles un demócrata, un agrario laborista, un socialista popular y una militante del PC. En 1953 por su parte triunfó nuevamente el radical Carlos Valdovinos, formando el consejo uno de sus correligionarios, un agrario laborista, un demócrata y un socialista popular.

La representación de unos y otros en la dirección comunal al parecer no fue fruto sólo de bien elaboradas campañas, observándose entre 1944 y 1953 la presencia territorial, con locales centrales y "comités" en diversos sectores de la comuna, de un variopinto espectro de organizaciones políticas. El Partido Radical, la colectividad de mayor peso electoral en la comuna en estos años, fundó el año 1946 en la población La Legua el Centro de Propaganda Alfredo Duhalde, el cual contaba con un club cultural y deportivo homónimo. Al año siguiente, parlamentarios radicales realizaron conferencias en la comuna y centros femeninos de la colectividad comenzaron a formarse, mientras que en el Club Radical desarrollaron sus actividades varios correligionarios que fueron parte del concejo municipal o directivos de organizaciones vecinales ${ }^{40}$.

Los democráticos, la segunda fuerza electoral, organizaron seccionales en varias poblaciones de la comuna, entre ellas en La Legua, Vicente Navarrete, Recreo, Germania y Colón - América, llegando a conformar una estructura de alcance comunal que tuvo una actividad muy productiva. Fuera de permitir la elección de regidores y alcaldes de sus filas, irradió hacia la juventud, existiendo su rama desde al menos 1945, cuando esta se hizo parte de la formación de un Comité de Unidad Juvenil. Los trabajadores fueron también su preocupación, conmemorando la "Fiesta del Trabajo" de 1948 con una velada literaria a la cual invitó a parlamentarios y autoridades de la colectividad. Y los vecinos siguieron siendo parte de sus bases, siendo invitados en febrero de 1950 a una reunión para promover la elección de René Aravena a regidor (en ese momento él era alcalde), quedando en el comité varios dirigentes vecinales ${ }^{41}$.

Los socialistas, que en estos años estaban construyendo las bases de su futura hegemonía en la comuna, impulsaron actividad en las poblaciones Recreo, Germania, La Legua, El Llano, Mirador, Atacama, Mussa y Santa Rosa de Macul, no sufriendo, según el diputado Mario Palestro, las divisiones y debilitamiento que sufrió su partido en estos años. Ello le permitió elegir a uno de sus destacados dirigentes sindicales al concejo municipal y más tarde al propio Palestro como diputado del distrito, sumándose protagónicamente

\footnotetext{
${ }^{40}$ Para la actividad de los radicales de San Miguel se pueden consultar La Comuna (órgano de la Unión Vecinal de San Miguel, 1942 a 1950), Lucha Obrera (marzo - agosto de 1948), El Diario Ilustrado y La Opinión, los dos últimos de circulación nacional, cubriendo la actividad de muchas organizaciones políticas.

${ }^{41}$ La aún importante pero dispersa actividad de los democráticos de mediados de siglo fue seguida por $\mathrm{La}$ Voz Democrática (del Centro de Estudios y Propaganda Juan Aravena Muñoz, 1949), Labor Democrática (del Centro Democrático Zenon Torrealba, 1949) y El Vocero (de la zona sur de Santiago, 1946). De circulación nacional, Las Noticias de Última Hora, La Opinión y Democracia.
} 
además a la primera candidatura de Salvador Allende. Su compañero habitual de alianza, el Partido Comunista, visibilizó menos sus locales y militantes por la situación política de la época, pero sus juventudes, que participaron de la formación de un Comité de Unidad en 1945, instalaron una sede en Gran Avenida en 1946, siendo además evidente la presencia de militantes comunistas o cercanos a esa organización en las poblaciones que participaron en el Frente Comunal de la Vivienda ${ }^{42}$.

El ibañismo, que reorganizó sus fuerzas a propósito de las nuevas ambiciones presidenciales del entonces senador Carlos Ibáñez, organizó un comité en enero de 1950 en La Legua Nueva, y al año siguiente, también en enero, dio origen al Centro Ibañista Femenino, ello a la par que el Centro Carlos Ibáñez del Campo de la comuna había comenzado a discutir su candidatura y el Movimiento Nacional Ibañista organizaba su directiva comunal a fines de febrero, participando en ella vecinos de la población Germania y colindantes a ella (sectores "Gran Avenida Norte" y "Berlín Norte") ${ }^{43}$. Por último, los conservadores, que según Palestro después de 1938 "de vez en cuando" elegían un regidor, mantenían organizada una sección femenina en la comuna en 1948 y en 1950 presentaron un candidato de la Vanguardia Obrera Conservadora al concejo, no manteniendo la representación que habían logrado en $1947^{44}$.

Como se ve, las corrientes políticas presentes en la comuna fueron notablemente más variadas que aquellas presentes en las estructuras intermedias y superiores de las organizaciones de trabajadores y pobladores, asumiendo además otras los roles hegemónicos, pudiendo acceder los obreros de MADECO, y no menor, sus familias, vecinos y grupos de pertenencia, a discursos y prácticas que no estaban del todo teñidos con la lógica del conflicto que predominaba en el espacio del trabajo.

\section{Las “otras” culturas sindicales. Demócratas, anarquistas y católicos}

Durante las primeras décadas del siglo $\mathrm{XX}$ diversas corrientes doctrinarias se expresaron al interior del movimiento obrero, y si bien hacia los años 40 se fue manifestado una mayor y más clara influencia de socialistas y comunistas, lo cierto es que hacia mediados del siglo los trabajadores disponían aún de un abanico de opciones para pensar y transformar sus condiciones de labor así como la sociedad en que estaban insertos.

En relación al Partido Democrático y su actividad sindical, el periódico La Opinión informó en marzo de 1946 de las decisiones que asumió el Directorio del Frente Sindical Democrático ante las divisiones que afectaban a su partido, debiendo pronunciarse además por las pugnas en la $\mathrm{CTCH}$, manifestándose a favor de la directiva presidida por el profesor socialista Bernardo Ibáñez, participando en el Consejo Directivo Nacional y Provincial de

\footnotetext{
${ }^{42}$ Los dos principales medios que seguían la actividad de los socialistas eran La Calle (1953 a 1955), del Partido Socialista Popular, y La Opinión. Más puntualmente, Democracia también dio cuenta de su accionar, al igual que Vivienda.

${ }^{43}$ Dos fueron los periódicos que más le prestaron atención al Movimiento Nacional Ibañista, La Opinión y El Imparcial, este último de vertiente social cristiana.

${ }^{44}$ El Diario Ilustrado, El Imparcial y La Batalla (editado por el Departamento Sindical de los conservadores los años 47 y 48) informaron de las actividades del viejo Partido Conservador.
} 
esa central al menos hasta 1950. El Directorio del Frente Sindical inició una serie de charlas y conferencias en mayo de 1946, invitando para aquellos efectos al presidente de la Central, Bernardo Ibáñez, y a medida que aunó voluntades con el sindicalismo socialista fue distanciándose del activismo del PC, llamando a sus bases en junio de 1947 a retirarse de las instancias sindicales mayores dirigidas por ellos. Los sindicalistas democráticos pudieron apoyarse en la estructura con la cual contaba su partido, manteniendo este a mediados de siglo en la capital 15 centros y algunos medios de prensa, aún cuando en ese plano estuvieron lejos de igualar la estabilidad de los medios comunistas y socialistas y la tozudez de los esfuerzos libertarios ${ }^{45}$.

También de las primeras y viejas influencias, la actividad de los libertarios en la mitad del siglo se mostraba fuertemente debilitada. Como señala Víctor Muñoz Cortés, en la década de los 40 la crisis del anarquismo se aceleró, sumándose a la pérdida de influencia social su crisis interna, desapareciendo o reduciéndose sus organizaciones, encontrándose "prácticamente desorganizada" la Confederación General de Trabajadores (CGT) cuando llevó a cabo su octavo congreso en marzo de 1948. A pesar de la debilidad objetiva, los libertarios trazaron y propusieron lineamientos, entre ellos impulsar la formación de un bloque sindical de organizaciones en resistencia y autónomas, debiendo estas luchar "en forma avanzada" por reivindicaciones económicas y sociales, y desarrollar "una amplia labor de extensión cultural en los medios populares".

En ambas líneas generales se avanzó, aun cuando sin mucha sistematicidad y dependiendo de algunos gremios o personalidades, todo lo cual le restó difusión y proyección a aquel accionar. Casi imposible de observar en la prensa de circulación nacional e incluso local, algunos trabajos, como el de Sebastián Allende, muestra cómo los obreros del cuero, tipógrafos y estucadores permanecieron cercanos al anarquismo y a las directrices de sus federaciones, colocando buena parte de sus esfuerzos en la reunificación del movimiento sindical, fundando e incorporándose a aquellos referentes que en esa dirección se formaron, como el Movimiento Unitario Nacional de Trabajadores (MUNT) en 1950, donde asumió como secretario general el anarcosindicalista Ernesto Miranda ${ }^{46}$. En el ámbito de la "amplia labor de extensión cultural", se mantuvo en funcionamiento algunos medios de prensa, sin duda muchos menos que antaño y con su clásica inestabilidad, circulando Germen en 1947, La Voz del Gráfico entre 1936 - 1945 y 1951 - 1952, La Voz del Ladrillero en los años 45 y 46, Siempre en 1948, La Voz del Gremio (de los obreros del cuero) entre 1943 y 1948 y Liberación en los años 1945 y $1949{ }^{47}$.

Sin nuevos bríos o en declive profundo la actividad de los trabajadores demócratas y anarquistas, los esfuerzos de los sindicalistas católicos se proyectaron más fructíferos, viéndose evidentemente beneficiados por las orientaciones que fue proyectando la Falange, por la creación de la Juventud Obrera Católica (JOC) en 1942 y muy particularmente por la formación de la Asociación Sindical Chilena (ASICH) en 1947.

\footnotetext{
${ }^{45}$ Semanario Democrático de Chile en 1948 y Labor Democrática y La Voz Democrática en 1949

${ }^{46}$ Sebastian Allende, Entre zapatos, libros y serruchos. Anarquismo y anarcosindicalismo en Chile (19201955), Santiago, auto edición, 2013. Ver "La creación de la CUT", pp. 119 a 122. Según Allende, al MUNT se incorporaron 12 federaciones, entre ellas la metalúrgica.

${ }^{47}$ Muñoz, op. cit. Ver anexo II, pp. 322 a 324.
} 
La Falange, que fue heredando los frutos de los "católicos sociales" y más tarde de los sindicalistas democráticos, realizó su Primer Congreso Sindical entre el 19 y el 21 de mayo de 1946, participando empleados, ferroviarios y suplementeros, siendo uno de los principales puntos del encuentro la capacitación sindical ${ }^{48}$.

La formación de los trabajadores fue la preocupación de la Acción Sindical Chilena, organizando formalmente su primera escuela en abril de 1950, manteniendo su actividad en el tiempo. La instrucción emprendida por la ASICH se complementó además con otras actividades y por otros medios, organizando por ejemplo un foro en octubre de 1951 sobre "Sindicalismo, personalismo y politiquería", mientras que por intermedio de su periódico, Tribuna Sindical, promovió el desarrollo del cooperativismo, uno de los ejes de trabajo de los socialcristianos ${ }^{49}$. Pero no todo fue capacitación para la ASICH, haciéndose crecientemente parte de las actividades del movimiento obrero, conmemorando en 1950, junto a la Juventud Obrera Católica, el $1^{\circ}$ de Mayo, asistiendo a su celebración poco más de 2.000 personas. Más tarde, entre el 9 y el 11 de enero de 1953, emprendió la realización de su II Congreso, definiéndose en él un conjunto de reivindicaciones y directrices para desplegar su labor sindical, destacando entre las primeras la igualación de la asignación familiar para obreros y empleados, la indemnización por años de servicio, la instauración del salario vital obrero y la solución integral del problema de la vivienda obrera, demandas amplia y evidentemente compartidas por los trabajadores. Además, se pronunció por la "terminación de la educación clasista" y la "co-gestión o co-gobierno industrial por los trabajadores", ideas que poco se explicitaron en los eventos de las CTCHs. Sobre las directrices, en el evento se definió que la calidad de dirigente gremial era incompatible con la calidad de dirigente o representante público de un partido político, colocándose en las antípodas del sindicalismo socialista y comunista, llamándose a la vez a no restringir la acción a la órbita de los sindicatos sino que a realizar "una obra de conjunto" 50.

Algunas de las definiciones tomadas en el II Congreso cobraron rápida expresión, formándose al mes siguiente en su local un "Comando unificado de lucha por las reivindicaciones obreras", integrándolo trabajadores del rubro alimentos, textil y metalúrgico, correspondiendo este último a Miguel Sanhueza, Subsecretario Nacional de la ASICH y presidente del sindicato obrero de MADECO, fijando como demandas principales un salario vital para todos los obreros y una asignación familiar similar a empleados ${ }^{51}$.

Por último, y en relación a lo que señalábamos al iniciar este punto, siendo mayoritarios los socialistas y comunistas entre los trabajadores organizados desde los años 40, sus fuerzas no eran ni homogéneas ni hegemónicas, reflejando el propio origen y primera composición de la Central Única de Trabajadores, fundada en febrero de 1953, la

\footnotetext{
48 Según Alan Angell, un miembro de la Falange, "Lorca", estaba incorporado al Comité Ejecutivo de la CTCH socialista en 1946. Ver en Partidos políticos y movimiento obrero en Chile, México, ediciones ERA, 1974, p. 186.

${ }^{49}$ Ver Tribuna Sindical, "Sindicalismo y Cooperativismo", № 8, segunda quincena de octubre de 1949, pp. 4 y 5 .

${ }^{50}$ Tribuna Sindical, "Contornos nacionales del segundo congreso de la ASICH”, año IV, febrero de 1953, N 40, pp. 4 y 5.

${ }^{51}$ Tribuna Sindical, "Se formó el Comando Unificado de Lucha por las Reivindicaciones Obreras", año IV, febrero de 1953, N 40, p. 6.
} 
existencia e incidencia de otras culturas sindicales en el movimiento obrero. Así, en la CUT confluyeron organizaciones variadas en composición y orientaciones, entre ellas de empleados públicos y privados, como la Agrupación Nacional de Empleados Fiscales (ANEF) y la Junta Nacional de Empleados de Chile (JUNECH), de mineros y obreros industriales, como los restos de las CTCHs, y los gremios anarcosindicalistas que en torno al MUNT habían iniciado el proceso, reflejándose esa variedad en la composición del primer Consejo Directivo Nacional, donde había diez socialistas (allendistas, populares y disidentes), cinco comunistas, tres anarcosindicalistas, dos radicales, dos ibañistas y dos falangistas, con un Secretario General - Clotario Blest - que había iniciado sus primeros pasos deslumbrado por Recabarren y por el cristianismo popular, sintiéndose a la vez espiritualmente cómodo con el anarquismo ${ }^{52}$. Y si esa diversidad ya era significativa, la elección de la directiva del provincial Santiago de la CUT, realizada a fines de junio de 1953, expresó aún más claramente la heterogeneidad de corrientes presentes entre los trabajadores, pudiendo votar los 867 delegados acreditados por cuatro listas, la formada por comunistas y radicales, el camino propio del Partido Obrero Revolucionario (POR), la amplia alianza de anarquistas, socialistas populares y trotskistas, y el acuerdo del Frente Cristiano junto a los Socialistas de Chile ${ }^{53}$.

\section{Conclusiones}

Como señalábamos en las primeras líneas, la historiografía marxista clásica relevó particularmente los vínculos existentes entre el movimiento obrero chileno y los líderes, orientaciones y organizaciones de vertiente socialista, proyectando la imagen de una identidad de clase asociada casi en exclusividad a las preocupaciones, prácticas y orientaciones del activismo comunista y socialista.

Sin discutir la influencia de los partidos de vertiente marxista en aquel proceso ni el predominio de los trabajadores comunistas y socialistas en los principales referentes gremiales a mediados de siglo, lo cierto es que, como muestra la experiencia de los obreros de MADECO tanto en su fábrica como en su entorno barrial, en estos años los trabajadores pudieron beber, y bebieron, de otras influencias, incorporando orientaciones no siempre similares a las del activo sindical, facilitándose ello por las muy variadas relaciones que establecieron desde la fábrica así como en la comuna por la cual circulaban o donde vivían.

Recordando a Raúl Nieto ${ }^{54}$, la clase obrera tiene una "existencia urbana", recogiendo influencias y viviendo experiencias que están "más allá de la vida laboral",

\footnotetext{
52 Según Homero Ponce, de los 2.355 delegados al Congreso Constituyente, había 503 comunistas, 600 socialistas, 150 radicales, misma cifra de "demócrata cristianos" (sic), 188 anarquistas, 18 trotskistas, 150 independientes y 589 "abstencionistas". Ponce, op. cit, p. 163. También, en Angell, op. cit, pp. 221 y 224.

${ }^{53}$ Según acusaba Tribuna Sindical, de los 867 delegados un 17\% se había abstenido de votar (147 aproximadamente), varios de ellos dirigentes cristianos. En aquellas elecciones, comunistas y radicales obtuvieron 6 consejeros, la alianza entre anarquistas, socialistas populares y trotskistas eligió a 4, el Frente Cristiano y los Socialistas de Chile consiguieron uno y el POR quedó sin representación. En Tribuna Sindical, "El provincial Santiago de la 'Central Única”", año IV, julio de 1953, N 435, p. 4.

${ }^{54}$ Raúl Nieto, Ciudad, Cultura y Clase Obrera. Una aproximación antropológica, México, Escuela Nacional de Antropología e Historia (ENAH), 1992.
} 
relacionándose su cultura con los procesos sociales implicados tanto en lo urbano como en el espacio del trabajo. En el caso de los obreros de MADECO, en la mitad del siglo XX su fábrica y los barrios donde vivían se asentaron en una comuna en pleno crecimiento industrial y habitacional, debiendo enfrentar problemáticas que, a la vez que los relacionaban con otros obreros y pobladores de San Miguel, los vinculaban con instituciones y sujetos que estaban fuera de la órbita tradicional del trabajo, como el municipio, los regidores y un amplio abanico de funcionarios del Estado.

$\mathrm{Si}$ bien las dinámicas comunales distaban de estar libres del conflicto, al concordarse en las demandas se abrió un espacio de colaboración entre los diversos actores, facilitándose ello por la amplia red de vínculos horizontales y verticales que se forjaban a nivel de la comuna (o a propósito de ella, como los diputados) y por la coincidencia entre estos de una noción de "progreso local" que promovía el trabajo mancomunado. De esta forma, el discurso y las prácticas de tintes más confrontacionales que se generaban en el espacio y ámbito del trabajo pudieron verse atenuados, abriéndose instancias de encuentro que, a la par que reforzaban tradiciones organizativas y solidaridades horizontales, mitigaban o matizaban el discurso de la lucha de clases.

Por último, en el espacio comunal los obreros de MADECO se encontraron con la protagónica participación y representación de fuerzas políticas que en sus direcciones gremiales mayores tenían roles secundarios o mínimos - radicales, demócratas e ibañistas -, las dos primeras con más de medio siglo de vida y las tres plenamente incorporadas en la dinámica política e institucional de la época. Difícil de medir la influencia que en ese momento tenían en el movimiento obrero y en los trabajadores de MADECO en específico, sí es posible suponerles una incidencia, en la comuna donde estos trabajaban y vivían, que no era meramente electoral, siendo parte de los referentes que promovieron el discurso de la cooperación y el progreso comunal que se fue haciendo visible en las organizaciones de trabajadores y vecinos de San Miguel hacia mediados de siglo. En relación a ello, es probable suponer que parte de las experiencias vividas por los trabajadores a nivel comunal reforzaron, por abajo, los procesos de institucionalización e "incorporación graduada" que venía impulsando el Estado desde fines de los 20 y de los cuales las propias organizaciones obreras se hicieron parte desde comienzos de la década del 30, representando la incorporación de la CTCH al Frente Popular un momento central en aquella política, matizándose o mitigándose la concepción esencialmente negativa que se portaba sobre el Estado y los sectores e instituciones dominantes.

\section{Bibliografía}

\section{Libros:}

Allende, Sebastian, Entre zapatos, libros y serruchos. Anarquismo y anarcosindicalismo en Chile (1920 - 1955), Santiago, auto edición, 2013.

Angell, Alan, Partidos políticos y movimiento obrero en Chile, México, Ediciones ERA, 1974. 
De Shazo, Peter, Trabajadores urbanos y sindicatos en Chile: 1902 - 1927, Santiago, DIBAM, 2007.

Grez, Sergio, El Partido Democrático de Chile. Auge y caída de una organización político popular (1887 - 1927), Santiago, LOM Ediciones, 2016

Hoggart, Richard, La cultura obrera en la sociedad de masas, Argentina, Siglo Veintiuno Editores, 2013.

Municipalidad de San Joaquín, Aquí hacemos historia: crónicas y relatos de San Joaquín, Santiago, 1995.

Muñoz, Víctor, Sin dios ni patrones. Historia, diversidad y conflictos del anarquismo en la región chilena (1890 - 1990), Valparaíso, Mar y Tierra Ediciones, 2013.

Pinto, Julio, y Valdivia, Verónica, ¿Revolución proletaria o querida chusma? Socialismo y Alessandrismo en la pugna por la politización pampina (1911 - 1932), Santiago, LOM Ediciones, 2001.

Pinto, Julio, Trabajos y rebeldías en la pampa salitrera, Santiago, Editorial Universidad de Santiago, 1998.

Ponce, Homero, Historia del movimiento asociativo laboral chileno, Santiago, auto edición, 1986.

Rojas, Jorge, La dictadura de Ibáñez y los sindicatos (1927 - 1931), Santiago, DIBAM, 1993.

Sagredo, Rafael, Escritos del Padre Fernando Vives Solar, Santiago, DIBAM, 1993.

Salinas, Maximiliano, Clotario Blest, profeta de dios contra el capitalismo, Santiago, ediciones REHUE, 1987.

\section{Artículos de revista:}

Sanhueza, Jaime, "La Confederación General de Trabajadores y el anarquismo chileno de los años 30", Revista Historia, vol. 30, Santiago, 1997.

Valdivia, Verónica, "Yo, el León de Tarapacá. Arturo Alessandri Palma, 1915 - 1932”, Revista Historia, vol. 32, Santiago, 1999.

\section{Tesis:}

Morales, Diego, El Paternalismo Industrial en la fábrica de Paños Bella-vista Tomé, 1910 1935, Santiago, 2013.

Nieto, Raúl, Ciudad, Cultura y Clase Obrera. Una aproximación antropológica, México, 1992.

Quinteros, Patricio, Antecedentes para una historia de la industria textil de Tomé durante la primera mitad del siglo XX, Concepción, 2001.

Stillerman, Joel, From solidarity to survival. Transformations in the Culture and Styles of Movilization of Chilean Metalworkers under Democratic and Authoritarian Regimes, 1945 - 1995, Nueva York, 1998.

\section{Periódicos:}

Democracia

El Siglo 


\author{
El Diario Ilustrado \\ El Imparcial \\ El Vocero \\ Labor Democrática \\ La Batalla \\ La Calle \\ La Comuna \\ La Opinión \\ La Voz Democrática \\ Lucha Obrera \\ Semanario Democrático de Chile \\ Tribuna Sindical
}

